\title{
2. Zeichen und Abkürzungen der Textedition
}

\section{a) Marginalien}

Die Kapitelzählung der vorliegenden Edition ist aus der Ausgabe des Benediktiners B. de Montfaucon übernommen, während die Paragraphenzählung neu eingerichtet wurde. Die Kolumnenzahlen der Edition de Montfaucons sind in der Marginalienspalte des Textes mit einem B gekennzeichnet, die des Neudrucks Mignes mit einem M.

\section{b) Text}

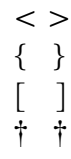

\{\}

[ ]
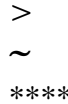

$+$

(A)*

$(\mathrm{A})^{\mathrm{c}}$

acc.

adscr.

ad loc.

al.

al. al.

al. $\mathrm{m}$.

ap.

a. $r$.

cet.

cf.

codd.

coll.

coni.

cont.

corr.

def.

del.

dist.

ditt.

em.

eras.

exp.

fort.

gl.

Zusatz durch Konjektur

Zusatz durch Retroversion einer Übersetzung

Tilgung nach Ansicht des Herausgebers

locus desperatus: Entscheidung war dem Herausgeber unmöglich

Kolumnenumbruch in der jeweiligen Edition

\section{c) Textkritischer Apparat}

omisit, -serunt

transposuit, -suerunt

litterae defectivae

addidit, -diderunt

(A) ante correctionem correxit (A)

accedente, accedit adscripsit, -serunt

ad locum

alii, alios locos, alibi

alii aliter

altera manus

apud

ante rasuram

ceteri

confer, -feratur

codices

collato

coniecit, -cerunt

contulit, -lerunt

correxit, -xerunt;

correctura

deficit, -ciunt

delevit, -verunt

distinxit, -xerunt

dittographia

emendavit, -verunt

erasit, -serunt

expunxit, -xerunt

fortasse

Glossa i. e.

in marg.

in ras.

ins.

i. t.

it.

lac. (ind.; stat.)

lect.

lin.

loc.

$\mathrm{m}$.

m. $r$.

mut.

n. 1 .

non leg.

pr. m.

prob.

rec.; recc.

s.

schol.

scr.

secl.

sim.

spat.

sq.

sup.

suppl.

transpos.

v. 1 . id est

in margine

in rasura

inseruit, -ruerunt

in textu

iteravit, -verunt

lacuna (lacunam indicavit;

statuit)

lectio, lectionem

linea, lineam

locavit, -verunt; locus

manus

manus recentior

mutavit, -verunt

non liquet

non legitur, -guntur

prima manus

probante, probantibus

recens, recentior;

recentiores

supra

scholium, scholia

scripsit, -serunt

seclusit, -serunt

similia, similiter

spatium, spatio

sequentem; sequentes

superscripsit, -serunt

superscriptum, -pto

supplevit, -verunt

transposuit, -suerunt

varia lectio 
EPISTULA AD MARCELLINUM 